\title{
CARTAS A MARINA: REPRESENTAÇÕES DE GÊNERO EM PAPEL E TINTA
}

\section{LETTERS TO MARINA: GENDER REPRESENTATIONS ON PAPER AND INK}

\author{
Ana Carolina Ferreira da Silva* \\ Clándia de Jesus Maia**
}

\begin{abstract}
RESUMO
Os anos de 1980 foram marcados pela consolidação de direitos femininos, oriundos de lutas feministas em décadas anteriores. Além disso, houve uma entrada expressiva de mulheres no mercado de trabalho, nos mais diversos setores, inclusive na imprensa brasileira, antes majoritariamente ocupada por homens. Neste artigo, analisamos a construção de representaçôes sociais em correspondências (cartas, cartões e bilhetes) endereçadas à apresentadora de TV Marina Queiroz, no periodo de 1980 a 1988. Ela foi a primeira mulher a comandar um programa dirigido ao público feminino, na extinta TV Montes Claros, hoje denominada Intertv, no norte de Minas. Analisando cartas enviadas à apresentadora, buscamos entender como ela foi representada pelo(a)s telespectadores(a)s. Para a análise, utilizamos alguns procedimentos da Análise do Discurso francesa.
\end{abstract}

PALAVRAS-CHAVE: Cartas. Gênero. Representações Femininas. Televisão.

\begin{abstract}
The 1980s were marked by the consolidation of women's rights, arising from feminist struggles in previous decades. In addition, there was an expressive entry of women in the labor market, in the most diverse sectors, including in the Brazilian press, previously mostly occupied by men. In this article, we analyze the construction of social representations in correspondence (letters, cards and tickets) sent to TV presenter Marina Queiroz, in the period from 1980 to 1988. She was the first woman to command a program directed to the female public, on the extinct TV Montes Claros, now called Intertv, in the north of Minas. We seek to understand how she was perceived and represented by the viewers, analyzing letters sent to this presenter. For an analysis, we used some procedures of French Discourse Analysis.
\end{abstract}

KEYWORDS: Letters. Gender. Female Representations. Television

\footnotetext{
* Jornalista da InterTV Grande Minas. Graduação em Comunicação Social / Jornalismo pela Universidade Federal de Juiz de Fora (UFJF). Pós-graduação em Jornalismo Digital pela Universidade Estácio de Sá. Mestre em História pela Universidade Estadual de Montes Claros (Unimontes).Email: anacarolmestranda@hotmail.com

** Professora da Universidade Estadual de Montes Claros (Unimontes). Doutorado em História pela Universidade de Brasília (2007), com período sanduíche na École des Hautes Études en Sciences Sociales (2006). Paris, França. Pós-doutorado na Universidade Nova de Lisboa com período na Université de Nice Sophia Antipolis, Nice, França (2014). Bolsista de Produttividade do CNPq. Email: claudia.maia@unimontes.br
} 


\section{INTRODUÇÃO}

O presente artigo tem por objetivo analisar as representações de gênero em correspondências (cartas, cartões e bilhetes) enviadas a Marina Queiroz, apresentadora na extinta TV Montes Claros, no período de 1980 a 1988. A correspondência privada permite que o/a historiador/a penetre não só no espaço privado, onde o feminino protagoniza, mas também em momentos de individualidade da constituição de sujeitos: "os modos de registros das mulheres estão ligados à sua condição, ao seu lugar na família e na sociedade" (PERROT, 2005, p. 39).

Nesse sentido, a carta é uma confissão formal assinada. Tanto para quem envia quando para quem recebe, é o instante em que se suprime o espaço, alimenta-se a memória e a imaginação naquilo que está ausente. A conservação das cartas significa dar importância a vínculos sociais estabelecidos, tanto afetivos quanto familiares. Ter esse tipo de documento conservado para uma análise historiográfica é muito precioso, quando se propõe a realizar história das mulheres. É notória a dificuldade em se reconstruir um passado no qual a atuação feminina nem sempre ganha a notoriedade merecida. No entanto, quando se consegue, abre-se a possibilidade de se repensar o papel feminino na história, a fim de se fazer existir, pois o que não ecoa no tempo é esquecido. É uma proposta de se repensar sujeitos, épocas e lugares de fala. A arte de historiografar mulheres é o "farejar da carne humana" no sentido mais profundo, defendido por um dos mestres dos Annales (BLOCH, 2002).

Essas fontes estavam guardadas em pastas plásticas, muito bem organizadas. Organização feita pela própria Marina. Compuseram, assim, um arquivo pessoal, o que revela um orgulho por esse tempo vivido. Segundo a própria Marina, as cartas armazenadas são as que se estão em melhor estado de conservação. Alguns documentos são cartas escritas em papel comum, folhas de caderno. Outras são cartões ou papel de carta. Algumas com logotipo de instituições, principalmente quando se dirigiam ao programa com sugestões de pauta e coberturas. Algumas possuíam uma escrita mais rebuscada, em português padrão, mas a grande maioria exibia uma escrita fora dos parâmetros da norma culta, expressando ser de pessoas menos escolarizadas. E, ao ter contato com um corpus documental tão relevante, consideramos a subjetividade na seleção dessas cartas. Uma fonte monumental, afinal, se houvesse algum texto ofensivo, este não foi arquivado por razões óbvias.

Ao todo, são 279 correspondências direcionadas a Marina ou ao programa Revista Feminina. As datas estão entre os anos de 1980 a 1988, período em que Marina Queiroz atuou como apresentadora. As correspondências ressaltam temas como a importância da posição que Marina ocupou, sua beleza e, em sua grande maioria, pedidos de divulgação de eventos, festas, convites para que a apresentadora participasse de festas diversas e sugestões de pauta, em geral, e, principalmente, temas muito falados e debatidos na década de 1980, como divórcio, aborto, emancipação feminina e outros.

Para a análise dessa documentação, utilizamos procedimentos da Análise do Discurso (AD) francesa, que nos permitiram analisar o objeto no nosso campo que é a História. Conforme Eni Orlandi, a $\mathrm{AD}$ não permite uma relação ingênua com a linguagem; nela, "procura-se compreender a língua 
fazendo sentido, enquanto trabalho simbólico, parte do trabalho social geral, constitutivo do homem e da sua história" (ORLANDI, 1999, p. 13).

Essa metodologia dialoga muito bem com a História, porque coloca a língua como ferramenta de construção de representações sociais quando tomada na forma do discurso. As condições de produção do discurso têm como características intrínsecas o social onde circula e a história; e esta, por sua vez, o enriquece por meio da construção de memória de um determinado grupo. "Dessa maneira, os estudos discursivos visam pensar o sentido dimensionado no tempo e no espaço das práticas do homem, descentrando a noção de sujeito e relativizando a autonomia do objeto da Linguística" (ORLANDI, 1999, p. 14). O discurso faz a mediação entre a realidade natural e a social e, por isso, tem a capacidade de promover manutenções e mudanças, movimentos e permanências, por meio da ação de dispositivos analíticos, como a paráfrase, a polissemia, o interdiscurso e a metáfora. E, se à história interessam os feitos humanos no tempo, nada mais oportuno do que se ter um recurso como Análise de Discurso para compreender como determinados simbolismos produzem sentido numa sociedade e, assim, as influências no real:

\begin{abstract}
A Análise do Discurso não estaciona na interpretação, trabalha seus limites, seus mecanismos, como parte dos processos de significação. Também não procura um sentido verdadeiro através de uma "chave" de interpretação. Não há esta chave, há método, há construção de um dispositivo teórico. Não há uma verdade oculta atrás do texto. Há gestos de interpretação que o constituem e que o analista, com seu dispositivo, deve ser capaz de compreender (ORLANDI, 1999, p. 25).
\end{abstract}

Levar em consideração esses mecanismos de produção discursiva e dimensionar o sentido do discurso no tempo e no espaço significa compreender o contexto histórico em um documento e como o discurso constrói um sentido, uma realidade. É apreender a produção de sentido de um grupo, a relação estabelecida com a ideologia presente e as regularidades do discurso. Por isso, é preciso pensar as condições em que o discurso acontece:

As palavras significam pela história e pela língua. Assim o dito está sempre constituído pelos já-ditos; por isso, a memória deve ser pensada em relação ao discurso, ou seja, como interdiscurso: aquilo que é produzido antes, em outro lugar, mas que está presente numa situação discursiva (MAIA, 2011, p. 58).

Portanto, se o que se busca são as palavras, significando pelo tempo e pela história na qual estão inseridas, e a pesquisa trata de história das mulheres, ao ler as missivas e analisá-las, conceitos importantes como gênero e representação social nortearam os percursos de análise. Entender esse jogo complexo pressupõe analisar o que significa uma mulher ocupar um lugar de fala de destaque, no interior de Minas, na década de 1980, trazendo um ineditismo para o que se entendia sobre o gênero feminino em um grupo social. É necessário compreender que as situações objetivas e as posições, fruto das representações sociais, não são mecanicamente construídas, mas sim culturalmente elaboradas e modulam o dito e o não dito: 
O discurso possui uma exterioridade que deve ser compreendida como forma de melhor delimitação do sentido produzido, ou seja, de que existe uma coerência interna ao discurso efetuado - aprofundado mais à frente - que só pode ser compreendida levando-se em consideração a ou as representações que influenciam nesta mesma produção. Assim, para se trabalhar com a análise de discurso e a teoria de representações sociais, na delimitação do objeto de estudo, deve-se ter em mente os diferentes objetos representacionais que podem estar presentes em sua construção, o contexto imediato que se configurou como cenário da coleta de dados e os acontecimentos políticos e culturais que cercam este mesmo momento da coleta (GOMES, 2015, p. 6).

Nas cartas, as representações sociais diversas no entorno da figura da apresentadora Marina Queiroz se fazem presentes e, por isso, o conceito de gênero ajuda a esclarecer os mecanismos de construções dos papeis masculinos e femininos; mecanismos sociais que estabelecem as diferenças sexuais (NICHOLSON, 2000). Ter o gênero como uma categoria de análise histórica, como propôs Scott (1989), é amadurecer e fortalecer esses caminhos, principalmente em âmbito acadêmico. Margareth Rago (1998) ressalta o quanto é importante, dentro da proposta de Scott, ir além de uma simples inclusão feminina na historiografia:

Mais do que a inclusão das mulheres no discurso histórico, trata-se, então, de encontrar as categorias adequadas para conhecer os mundos femininos, para falar das práticas das mulheres no passado e no presente e para propor novas possíveis interpretações inimagináveis na ótica masculina (RAGO, 1998, p. 92).

Tornar o inimaginável possível é abrir fissuras e colocar no palco da vida novos discursos. Gênero como categoria de análise histórica permite compreender, de forma mais ampla, a construção dos papéis sexuais, em diferentes tempos; compreender esses mecanismos é, também, uma estratégia de desconstrução e mudança. É redefinir os padrões do que é ou não é relevante na história. Considerar o gênero dessa forma é, de fato, fazer a inclusão das mulheres no processo histórico, recusando-se a aceitar espaços delimitados previamente ao sexo feminino nessas narrativas e, assim, reescrever a historiografia. E fazer essa discussão é permitir que várias outras categorias, até então excluídas dos relatos históricos, façam-se presentes. Não basta apenas escrever sobre as experiências femininas, mas é preciso compreender os mecanismos que as colocam em posições de inferioridade. E. para isso, o gênero se mostra eficiente:

O gênero se torna, aliás, uma maneira de indicar as "construções sociais" - a criação inteiramente social das ideias sobre os papeis próprios aos homens e às mulheres. É uma maneira de se referir às origens exclusivamente sociais das identidades subjetivas dos homens e das mulheres. O gênero é, segundo essa definição, uma categoria social imposta sobre um corpo sexuado. Com a proliferação dos estudos do sexo e da sexualidade, o gênero se tornou uma palavra particularmente útil, porque ele oferece um meio de distinguir a prática sexual dos papéis atribuídos às mulheres e aos homens. [...] O uso do "gênero" coloca a ênfase sobre todo um sistema de relações que pode incluir o sexo, mas que não é diretamente determinado pelo sexo nem determina diretamente a sexualidade (SCOTT, 1989, p. 7). 
O conceito de representação social, sob a influência da psicologia social de Serge Moscovici, foi essencial para este estudo, uma vez que este autor o compreende como um fenômeno. ${ }^{1}$ Para Moscovici (2013), as representações sociais estão muito ligadas ao processo de comunicação e à produção de conhecimento, onde há a interação entre os indivíduos conectados por discursos. Leva em consideração todo um processo no qual o ser humano é agente de mudança mas, também, é produto da sociedade na qual está inserido.

Marina Queiroz era uma apresentadora de TV, ou seja, estava inserida em um veículo de comunicação e a mídia faz com que representações sociais se tornem senso comum, influenciem a constituição de realidades porque faz com que determinados assuntos se insiram nos diálogos mais corriqueiros. As narrativas constituem o processo de historicização e é nesse campo da linguagem que a história se constitui. Essa mesma linguagem estrutura discursos e esses discursos materializam as representações sociais.

Para Serge Moscovici (2013), a compreensão de representação social implica em perceber que não se trata apenas de um conceito; é algo além disso, está na sociedade e a transforma também. Representações sociais nascem, recriam-se, morrem ou dão origem a outras nesse contexto de sociedade. Moscovici busca compreender a dinâmica interna de formação dessas representações, pois compreende que elas não são algo estático:

Representações, obviamente, não são criadas por um indivíduo isoladamente. Uma vez criadas, contudo, elas adquirem uma vida própria, circulam, se encontram, se atraem e se repelem e dão oportunidade ao nascimento de novas representações, enquanto velhas representações morrem (MOSCOVICI, 2013, p. 41).

Ao analisar o texto acima, de Moscovici, vemos que as representações sociais são dinâmicas e podem sofrer mudanças, assim como o discurso. Um importante ponto de aproximação entre a análise de discurso e a teoria da representação social é a ideologia porque traz consigo uma cosmovisão estabelecida e que vai gerar construção simbólica de objetos representacionais (GOMES, 2015). E os sujeitos protagonizam este processo por meio da reformulação discursiva que se dá pelas lentes através das quais o sujeito vê e apreende a sociedade. Percebe-se o poder desse fenômeno, que vai compondo a

\footnotetext{
${ }^{1}$ A teoria das representações sociais de Moscovici defende que percebemos o mundo tal como ele é, no entanto, simbolizamos seres e objetos diante da necessidade de compreender essa realidade. Algumas representações ocorrem de maneira automática, pela capacidade de ancoragem e adaptação ao meio onde estão inseridas. Outras possuem invisibilidade porque há uma fragmentação pré-estabelecida, repartição que está ligada a fatores históricos, culturais e sociais. Todos estão cercados individualmente ou coletivamente por palavras, ideias e imagens que nos influenciam sem sabermos sequer a origem, em um processo de "naturalização" muito eficiente que nos faz crer que sejamos autores de determinado discurso (MOSCOVICI, 2003). A teoria das representações sociais é considerada uma abordagem sociológica da Psicologia Social e é vista como uma teoria que responde melhor as análises contemporâneas dos fenômenos sociais, uma vez que as sociedades se tornaram mais complexas. O pluralismo e a rapidez nas mudanças se fazem cada vez mais presentes e nem todas as representações são verdadeiramente coletivas. A teoria das representações sociais de Moscovici foi uma importante contribuição para a compreensão dos fenômenos coletivos sem deixar de levar em conta as individualidades que também compõem estes sistemas (FARR, 2012). Seres humanos são diferentes e parecidos ao mesmo tempo e o discurso se faz necessário para conectarmos e promover a comunicação (JOVCHELOVITCH, 2012). De acordo com Gomes (2013, p, 13), "a palavra é um fenômeno ideológico por natureza [...] Adota-se a hipótese de que a consideração da relevância da dimensão ideológica das palavras nos estudos em representação possa aprofundar ainda mais as características dos processos sociocognitivos, onde contextos representacionais possam iluminar os sentidos presentes nos processos discursivos acerca de um determinado objeto."
} 
realidade de uma maneira bem contundente. Não é fácil confrontar as ideologias, uma vez que possuem uma história de constituição, com conteúdos e valores. A imprensa pode ser interpretada como um poderoso dispositivo social que produz, reforça e faz circular discursos diversos. Logo, a conquista de espaço feminino na imprensa possui a sua historicidade e relevância social; afinal, as representações sociais:

[...] entram para o mundo comum e cotidiano em que nós habitamos e discutimos com nossos amigos e colegas e circulam na mídia que lemos e olhamos. Em síntese, as representações sociais sustentadas pelas influências sociais da comunicação constituem as realidades de nossas vidas cotidianas e servem como o principal meio para estabelecer as associações com as quais nós nos ligamos uns aos outros (DUVEEN, 2013, p. 8).

Dentro de jogos de forças no espaço midiático, estas representações sociais reforçaram estereótipos, típico do cotidiano das notícias, mas também promovem rupturas. Essas transformações se dão pelo campo das formações ideológicas, muito sensíveis ao processo das transformações sociais.

Segundo Gomes (2015), na estrutura do pensamento social a ideologia ocupa um lugar primeiro e as representações sociais desempenham um importante papel de comunicação entre a ideologia e as formações discursivas em um contexto espaço-temporal. Por isso é possível ter uma explicação consistente para a dinâmica das relações, compreendendo melhor como se dão as interações sociais, os simbolismos e a construção de uma identidade grupal. Se bem associadas, a Análise de Discurso e a Teoria das Representações Sociais podem mostrar que o processo discursivo não é mecânico e está em conformidade com a exterioridade do discurso. É neste contexto que os sujeitos, em sua produção de sentido, numa atitude discursiva, trazem em seus discursos uma identidade; elemento importantes para a compreensão dos objetos representacionais que os constituem. $\mathrm{E}$ as identidades discursivas possuem variáveis, como identidade de distanciamento, de engajamento, de sedução, de polemização e outras:

\footnotetext{
Os estudos em representações sociais são promissores para uma melhor delimitação desses conceitos e por sua integração na análise do discurso francesa para se entender a estrutura de um determinado pensamento social - no caso, as representações -, o modo como este pensamento é verbalizado nas intenções cotidianas, a forma como são adotadas as atitudes no processo de comunicação e as práticas sociais e discursivas desenvolvidas no conjunto das interações desses processos (GOMES, 2015, p. 14).
}

As cartas destinadas a Marina Queiroz são uma importante fonte que permite ter acesso a sentidos produzidos em uma época. A análise de discurso vai possibilitar que se explicite a lógica interna e a estrutura de organização dos discursos presentes nas missivas, proporcionando compreender a construção de representações de gênero e a produção de sentido sobre a apresentadora Marina Queiroz.

\section{OS PROGRAMAS PARA MULHERES}

Embora, nos anos de 1970, a televisão já fosse uma realidade no Brasil, os telespectadores de Montes Claros sofriam muito com a qualidade do sinal que chegava. Era uma retransmissão da TV Itacolomi, de Belo Horizonte. Alguns empresários influentes da cidade movimentaram-se para que a 
cidade possuísse repetidoras de sinal em pontos estratégicos para se alcançar mais qualidade. No entanto, Elias Siufi, influente diretor da Rádio Sociedade, convenceu os empresários de que o melhor seria lutar por uma concessão de televisão, para trazer uma emissora para Montes Claros. O fim da década de 1970 e começo dos anos de 1980 foram marcados, no universo das telecomunicações, como épocas em que muitas concessões de rádio e TV foram liberadas. ${ }^{2}$

Em setembro de 1980, a TV Montes Claros entrou no ar. Na programação, a retransmissão da programação da TV Bandeirantes, mas também conteúdo local, como telejornais e o programa Tarde Mulher que, posteriormente, veio a se chamar Revista Feminina. Para o departamento de jornalismo, houve a contração de três mulheres: Lígia Rocha Tupy, que seria a responsável pelos telejornais, sendo a editora desses conteúdos; Marina Queiroz, que fez um teste para ocupar os cargos de apresentadora e também de produtora de conteúdo do programa Tarde Mulher, e, menos de dois meses depois, Rosângela Silveira foi incorporada à equipe de produção de conteúdo, principalmente para o programa apresentado por Marina. No entanto, cabe ressaltar que o programa apresentado por Marina, ainda que tratasse de temas importantes, era considerado um produto específico, ameno, para mulheres. A recém inaugurada TV Montes Claros tinha em sua grade os telejornais locais, como foi dito acima, e todos eles eram apresentados por homens. Estes iam apenas à emissora para a apresentação. Eram as mulheres que ficavam em tempo integral, produzindo a maioria do conteúdo transmitido; no entanto, os lugares de fala que transmitiam uma maior credibilidade, as principais notícias do dia, eram ocupados por homens.

É importante ressaltar que, durante o período em que Marina esteve na TV Montes Claros, ela se afastou por três vezes para disputar eleições. Duas vezes se candidatou como deputada estadual e uma vez concorreu à prefeitura de Montes Claros. Foi presidente do PDT Mulher, regional Norte. O que se nota é que, à frente desse programa, estava uma mulher com uma formação intelectual sólida, pois era formada em sociologia, com experiência nas artes cênicas e muito articulada socialmente, uma combinação que reunia elementos relevantes. Durante o tempo que trabalhou na TV Montes Claros, à frente do programa Tarde Mulher, houve uma resposta muito positiva a esse produto. O programa, posteriormente chamado de Revista Feminina, agradava a um público diverso. Era possível vender bem os espaços comerciais. Se o programa, de fato, conseguia atingir uma parcela considerável do público e Marina Queiroz era um dos principais destaques da TV Montes Claros, as cartas eram um termômetro interessante para avaliar a maneira como o conteúdo impactava o telespectador.

Antes de começar a analisar as cartas, faz-se necessário conhecer um pouco como os programas voltados para o público feminino surgiram no espaço televisivo. Entender isso é compreender, também, o programa que fez com que as correspondências aqui analisadas fossem escritas. O programa Revista Feminina, entendido como um produto a ser consumido, precisava seguir padrões já estabelecidos nacionalmente e que eram casos de sucesso. Como foi dito acima, este período histórico foi marcado

\footnotetext{
2 Segundo o portal Intervozes, ao todo 634 canais de radiodifusão foram liberados no governo de Figueiredo, entre 1979 a 1985. Desse total, 40 eram de emissoras de TV. E essas distribuições foram marcadas por um clima de desconfiança de fraudes e favorecimentos (MIELKE, MOREIRA, PITA, 2014).
} 
por profundas transformações em valores sociais, legislação, conquistas de direitos femininos, além da produção científica dos estudos de gênero em universidades. E, segundo Moscovici (2013), a ciência é uma fonte fértil de novas representações sociais. Entravam em circulação na sociedade, novos discursos, com proposições de espaços e lugares há algumas décadas reivindicados pelos movimentos feministas.

Na perspectiva da Análise de Discurso, podemos dizer que famílias discursivas consecutivas, mantidas pelo processo de paráfrase, retornando sempre ao mesmo espaço do dizível, se estruturaram como discurso polissêmico até que se tornaram, também, uma representação estruturada de um discurso parafrástico. Afinal, passou a ser normal, em alguns aspectos, a ocupação de determinados lugares por mulheres e o exercício de alguns direitos. Estes programas, em sua maioria, traziam em seu conteúdo a discussão destes processos, de transformação ou de consolidação.

A televisão brasileira, desde a sua inauguração, percebia o potencial econômico que os programas destinados às mulheres possuíam. Quando esse formato de programa chegou ao Brasil, em 1950, as mulheres ficavam muito tempo em casa e, devido ao protagonismo no ambiente doméstico, seria interessante pensar em uma programação para quem estaria sempre próxima a um aparelho de TV. As mensagens transmitidas a esse público são discursos que as enxergam como consumidoras, mas também as produzem e constituem como produto a ser consumido.

Se há a aparente impressão de que uma emissora vende seus programas para o público em geral, é preciso lembrar que a venda é em outro sentido. O que uma emissora vende de fato é o seu público, sua audiência que é "comprada" pelo anunciante, sob a forma de tempo na programação (ALMEIDA, 2003, p. 88).

Ainda que, naquela época, muitas mulheres não tivessem uma autonomia financeira, no universo do privado as opiniões delas eram relevantes, uma vez que eram elas as responsáveis pelos cuidados com casa e com filhos e, por isso, conhecedoras de suas necessidades. O mercado, atento a este contexto, investia em propagandas e publicidades eficientes para que elas convencessem os maridos a comprar tais produtos. Os primeiros programas femininos surgiram com apresentadoras que já faziam publicidade e eram conhecidas no rádio. Além disso, tinham conteúdos voltados para o universo privado: culinária, artesanato, musicais, entrevistas e prestação de serviço. Temas considerados tabus não eram tratados.

O primeiro programa voltado para o público feminino na TV brasileira foi o Revista Feminina, comandado por Lolita Rios, no período da tarde, no início da década de 1950, na TV Tupi. É importante ressaltar que os anos cinquenta foram uma época em que se ensaiavam mudanças mais profundas sobre os comportamentos femininos, que viriam de fato nos anos de 1960, 1970 e 1980. Mais do que reforçar estereótipos, os programas femininos eram espaços também para inserção de discursos de mudança, de produção de novas formas de comportamento, como se constatou em décadas posteriores à de 1950.

Diante dessas transformações, principalmente nos anos de 1980, quando os movimentos feministas tiveram um papel de reconfiguração das relações sociais, além do aumento da escolaridade e da inserção da mulher no mercado de trabalho, viu-se, na imprensa, de um modo geral, um replanejamento dos programas voltados para o público feminino. Respondendo às demandas da década 
de 1980, destaca-se nesse conjunto midiático, o programa TV Mulher, da Rede Globo, que foi ao ar em abril de 1980 com um conteúdo em sintonia com o contexto da época, explicitando o universo feminino. As mulheres e as transformações em que elas estavam inseridas ocupavam o centro das pautas do programa e foi um sucesso de audiência e faturamento. ${ }^{3}$

Um ano depois da estreia, a Globo ampliou o tempo do programa diário, comandado por Marília Gabriela. Eram quadros que falavam sobre direitos sociais, sexualidade e, também, sobre assuntos mais tradicionalmente comuns ao universo feminino, como moda e beleza. Explicam Flávio Ricco e José Vannucci (2017, p. 142):

O programa tinha como fio condutor o comportamento da nova mulher e, nesse sentido, todos os produtores, jornalistas e redatores buscavam pautas que mostrassem essas mudanças que ocorriam na sociedade e quais seriam seus impactos nas gerações futuras.

O TV Mulher se tornou referência de programa feminino e inspirou diversos outros programas em todo o país e em diferentes emissoras, tornando-se obrigatório nas programações das afiliadas da Rede Globo. Esse programa permaneceu no ar até 1986 e, em apenas três anos de existência, consolidouse como um produto de sucesso. Portanto, a Rede Globo determinou que suas afiliadas fizessem programas parecidos ou tivessem em seus telejornais conteúdos do mesmo estilo (RICCO; VANNUCCI, 2017).

Ainda que a TV Montes Claros, nos seus sete primeiros anos, estivesse afiliada à TV Bandeirantes, o programa apresentado por Marina Queiroz seguia o modelo reproduzido pela Rede Globo. Ambos os programas eram compostos por reportagens e entrevistas ligadas a temas muito importantes para a década de 1980, como divórcio, independência feminina e avanço da mulher no mercado de trabalho, aborto, além de diversidades culturais. Em 1987, a TV Montes Claros passou a ser afiliada à Rede Globo e fez alguns ajustes de adequação de padrão; no entanto, o produto permaneceu na casa. Mesmo que, na Rede Globo, o TV Mulher tivesse saído do ar um ano antes, em 1986, o formato era sucesso consolidado e continuou em outras emissoras no país. Isso pode ser percebido na comparação entre esses dois produtos nas Imagens 1 e 2:

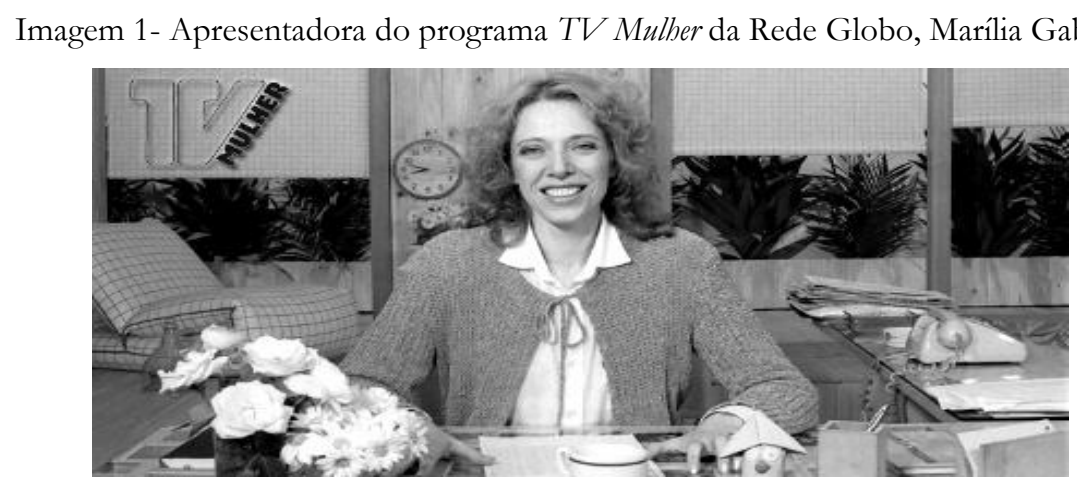

Fonte: Memória Globo, 1980

${ }^{3}$ Para mais detalhes sobre o histórico dos programas femininos na televisão brasileira, cf, Ricco e Vanucci (2017). 
Imagem 2 - Apresentadora do programa Revista Feminina Marina Queiroz, 1987

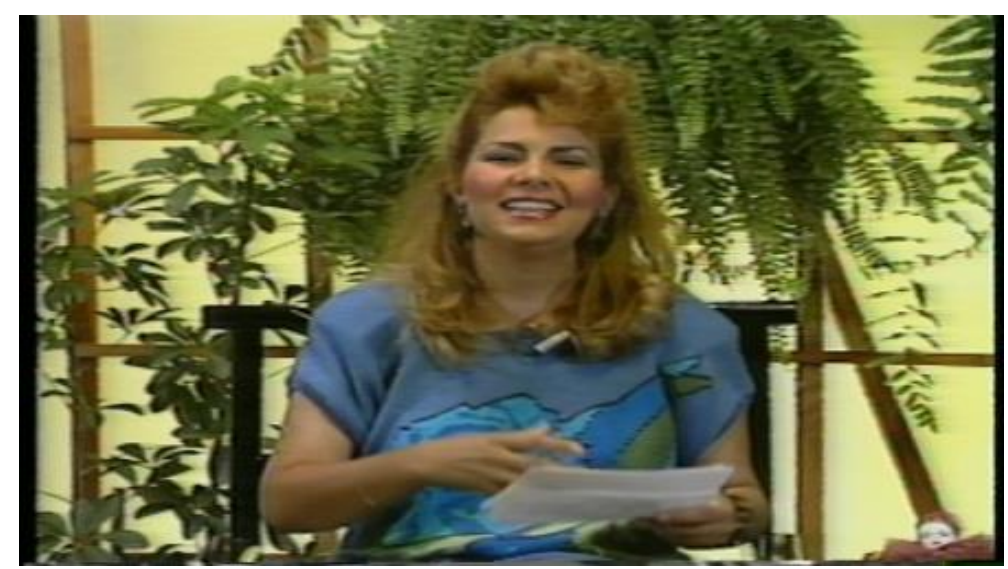

Fonte: Arquivo Intertv Grande Minas

Embora a Imagem 1 esteja em preto e branco e a Imagem 2, colorida, notam-se, claramente, as semelhanças entre os dois programas, dadas as devidas proporções de estrutura entre uma emissora afiliada e uma emissora principal. Percebe-se que tanto Marília Gabriela quanto Marina Queiroz estão inseridas em um cenário que remete a um ambiente doméstico, que lembra a sala de estar de uma casa. Os penteados, seguindo a moda dos anos de 1980, marcavam o perfil de mulher mais moderna e imponente. As roupas são do mesmo material, o crochê, que dão às apresentadoras elegância e sobriedade, mas com leveza, exigidas num programa televisivo desse tipo. A maquiagem de ambas segue o padrão televisivo, apenas para realçar a beleza natural do rosto, sem dar um aspecto pesado. ${ }^{4}$

Nas imagens, ambas as apresentadoras são brancas, loiras, de olhos claros e aparecem sorridentes, com um ar de naturalidade, características muito exigidas de quem se dispunha a ser apresentadora de programas femininos. Conforme Ricco e Vannucci (2017, p. 139), "a naturalidade das apresentadoras é algo fundamental nos programas femininos transmitidos ao vivo e um elemento que sempre esteve presente no decorrer desses 67 anos de televisão no Brasil”. No cenário de Marília Gabriela (Imagem 1) há vários elementos de decoração, como almofadas, flores, relógio de parede e até um telefone. O cenário de Marina Queiroz (Imagem 2) tem menos elementos de decoração, mas conta com plantas, uma cadeira e uma bonequinha de louça no canto direito, ou seja, elementos que simbolizam o universo feminino.

O TV Mulher e o Revista Feminina abordavam temas parecidos, mas, por se tratar de um programa de uma TV regional, o segundo também abria espaço para a cultura da região, levava convidados para dar entrevistas de temas ligados ao cotidiano do Norte de Minas, cantores se apresentavam e especialistas, nas mais diferentes áreas, como médicos, advogados e outros, sempre eram convidados a participar para debater determinados assuntos. Algumas cartas endereçadas a Marina ou ao programa

\footnotetext{
4 O texto "O eu, o corpo e a moda: reflexos dos anos 80 (OLIVEIRA $e$ al, 2015) propõe-se a descrever o que era moda e estética femininas nos anos 1980. Algumas descrições vão ser semelhantes a aspectos apresentados nas fotos das apresentadoras; no entanto, as extravagâncias em maquiagem e roupa, típicas da década, não serão vistas, uma vez que entram em conflito com padrões da televisão, que mescla aspectos da moda e de padrões estéticos que possam interferir na transmissão de informação.
} 
eram lidas em diferentes momentos. As que estavam relacionadas a eventos ou apenas recadinhos de telespectadores fiéis ao programa eram lidas mais ao final. No entanto, como veremos mais adiante, havia cartas com narrativas muito pessoais e íntimas, de telespectadores(as) que desabafavam com Marina. Estas não eram divulgadas. Entendido o perfil editorial do programa e o contexto histórico no qual estava inserido, é possível compreender as muitas cartas que chegavam, todos os dias, à emissora situada no bairro Morrinhos, em Montes Claros. O programa, apresentado por Marina Queiroz, era um modelo de produto muito bem sucedido em rede nacional, neste caso, o TV Mulher. ${ }^{5}$

\title{
O QUE DIZEM AS CORRESPONDÊNCIAS...
}

Das 279 correspondências do Arquivo Pessoal de Maria Queiroz (APMQ), selecionamos cinco cartas para a análise no presente artigo. Por meio do estudo, foi possível perceber o que se entendia na década de oitenta como características inerentes ao gênero feminino, sejam elas as mais tradicionais, cristalizadas, ou aquelas que deixavam claras as mudanças da época. Esses elementos compunham as mais diversas representações sociais criadas em torno de Marina Queiroz, apresentadora de TV.

A carta que trataremos a seguir faz referência a direitos sobre questões conjugais. O programa sempre contava com profissionais de diferentes áreas de atuação que cediam entrevista para falar sobre os temas selecionados, nesse caso, a área jurídica:

\begin{abstract}
Sou casada a 41 anos, na Igreja e no cartório em comunhão de bens. Casamento de véu, grinalda, convite e tudo e vivemos até hoje bem graças a Deus com nossos filhos. Aos 12 anos casei-me na Igreja e aos 18 no cartório mas na época não fui orientada que precisava do sobrenome do meu marido, então assinei e assino só o meu, até hoje conforme nos papéis, mais eu acho que assim não fica bem e mais tarde se meu marido faltar primeiro, tenho receio que isso venha me prejudicar financeiramente, e, por isto peço resposta e desde já agradeço ao Dr. Arnaldo Ataides Dias e a você Marina. Da esposa indecisa (APMQ. Carta anônima, maio de 1984).
\end{abstract}

Temos aqui uma esposa, que preferiu não se identificar, que se mostra constrangida pelo fato de não ter o sobrenome do marido. Levando em consideração que o ano é 1984 e o casamento ainda dava à mulher uma posição social de respeito, percebe-se que ela está preocupada, não apenas com a questão da herança, mas com a reputação: o olhar do outro, pois ter o sobrenome do marido significa deixar claro para a sociedade que ela era casada. Há que se levar em conta, também, que se trata de uma mulher mais velha, com idade de 53 anos, conforme os dados da correspondência: 41 anos de casada, endo se unido ao marido aos 12. É importante que se observe a idade com que se casou: apenas doze anos, o que releva seu pertencimento a uma família que se preocupava em dar esse tipo de destino às

\footnotetext{
${ }^{5}$ O TV Mulher permaneceu no ar até 1986 e somente a partir de seu terceiro ano é que se transformou numa atração obrigatória para todas as emissoras e afiliadas da Rede Globo. Em algumas praças, apresentadores locais comandavam blocos regionais com notícias e reportagens direcionadas especialmente para essas cidades, uma forma de aproximar as telespectadoras (RICCO E VANNUCCI, 2017, p. 145). É importante ressaltar que a TV Montes Claros, no ano 1987, passou a ser uma afiliada da TV Globo. Até então, retransmitia o sinal da TV Bandeirantes, o que indica que este tipo de programa, voltado para o público feminino, não era apenas um modelo da Globo ou de suas afiliadas. Estava presente em outras emissoras, conforme apontam Ricco e Vannucci (2017)
} 
mulheres. Pela data da carta, ela teria nascido em 1931, ou seja, nas primeiras décadas do século XX, quando o casamento já tinha sido reformulado como uma instituição burguesa muito importante para se garantir a ordem pública (MAIA, 2011). Nesse processo de reconstrução do sentido do matrimônio, o status de casada era concebido como sinônimo de felicidade e realização plena para as mulheres. Logo, é perceptível, à autora da carta, que ter o sobrenome do marido era uma garantia de comprovação de que ela se encaixava nesse modelo burguês desejado. Ela ainda não tinha o sobrenome do esposo, mas fazia questão de deixar claro na carta que é casada nas duas instâncias, civil e religioso, e que todos os ritos foram rigorosamente cumpridos, além da existência de filhos, o que legitima a união além de destacar as simbologias que compõem o cenário: "Casamento de véu, grinalda, convite e tudo e vivemos até hoje bem graças a Deus com nossos filhos."

Os anos de 1980 são marcados pelo surgimento de debates abordando temas polêmicos, como divórcio e aborto. O programa Revista Feminina também era solicitado para discutir esse tipo de assunto, tão em evidência na época. Em uma das cartas do arquivo de Marina Queiroz, um médico se oferece para participar do programa como entrevistado, a fim de prestar esclarecimentos às telespectadoras. $\mathrm{O}$ médico que datilografou a carta, fez questão que as sugestões fossem escritas em letras maiúsculas, para dar ênfase aos temas que gostaria de tratar. A carta é de 24 de abril de 1982. Sugere ele:

Faça, por exemplo, uma discussão entre dois ou três médicos, ou com a participação de 2 ou 3 médicos, aborde um tema como ABORTO, ou TÓXICOS, ou SAÚDE no sentido amplo da palavra (APMQ. Carta de J. A. G. M., abril de1982).

Faz-se relevante destacar que o médico sugere que outros médicos sejam convidados a debater os assuntos, ou seja, todos os debatedores seriam de uma mesma profissão. O médico restringe o debate sobre o aborto apenas aos médicos, possivelmente outros homens, deixando de fora desse debate as principais interessadas, que são as mulheres. Caso a entrevista ocorresse no programa nos padrões sugeridos pela carta, Marina talvez fosse a única mulher no processo; no entanto, como apresentadora, ela intermediaria a entrevista e não opinaria.

É importante compreender o motivo de uma carta, com uma sugestão dessa, ter chegado até Marina Queiroz na década de 1980. Esse período foi marcado pelo debate público sobre o aborto e o ano de 1983 foi um marco sobre essa discussão, com um encontro sobre saúde, sexualidade, contracepção e aborto organizado pela Casa da Mulher no Rio de Janeiro. Segundo a advogada Leila de Andrade Linhares Barsted (1992), a época foi marcada pela mobilização de mulheres em defesa do direito ao aborto, conforme o slogan "Nosso corpo nos pertence". O discurso tomou dimensão política e era impossível de ser ignorado. Os setores religiosos aturam fortemente contra qualquer possibilidade de aprovação, seja nos bastidores da política ou por um forte marketing na grande imprensa. Sozinhas, feministas abriram um debate ferrenho em torno desse tema, mas se viram pouco apoiadas. Conselhos regionais de medicina, $\mathrm{OAB}$, sindicatos, intelectuais se mantiveram indiferentes ao assunto. " $\mathrm{O}$ Congresso Nacional não aprovou nenhum dos projetos apresentados sobre a matéria aborto, em que pese a representatividade política de parlamentares como Cristina Tavares, José Genoíno e Luiz Alfredo 
Salomão" (BARSTED, 1992, p. 124). Numa época em que direitos femininos se consolidavam, a mulher avançava na presença no mercado de trabalho, mas a discussão sobre esse tema esbarrou no moralismo.

Para a antropóloga Débora Diniz, defensora da descriminalização do aborto e estudiosa desse tema, houve uma atuação diferenciada frente aos temas da contracepção e do aborto nesse período.

\begin{abstract}
Além dos efeitos da criminalização, a permanência da moral cristã, que descreve o aborto como um pecado, contribui para o silêncio das mulheres em torno do assunto. A resistência da Igreja Católica aos métodos contraceptivos nem de longe se assemelha à intensidade com que ela e outras Igrejas cristãs repudiam o aborto. Muito embora ainda considere os métodos contraceptivos "vias ilícitas para a regulação dos nascimentos", a Igreja Católica gradativamente reduziu a resistência aos chamados "métodos modernos de contracepção" para concentrar esforços na condenação moral e política do aborto. Porém, mesmo entre o crime e o pecado, as mulheres produziram saberes, difundiram práticas e rotinas para o cuidado com o corpo (DINIZ, 2012, p. 315).
\end{abstract}

Há também um fator sobre as condições de produção de discurso que precisa ser levado em conta: a relação de forças estabelecidas quando temas polêmicos entram em discussão, conforme apontado pelas duas autoras acima citadas. Isso está ligado ao lugar de fala e define relações sociais de poder. Por isso, é importante destacar que o discurso sobre o aborto, ao ser proferido por médicos, é legitimado. Mais do que o posicionamento social que eles ocupam, a medicina como um dispositivo de produção de discursos de verdade, faz com que esses profissionais possuam um aval social para a sua falas "São essas projeções que permitem passar das situações empíricas - os lugares dos sujeitos - para as posições dos sujeitos no discurso. Essa é a distinção entre lugar e posição" (ORLANDI, 1999, p. 38).

Em outra carta selecionada para a análise, a missivista faz um pedido de emprego que é, ao mesmo tempo, um desabafo. A autora, M. J. não só pede o emprego como descreve a sua vida conjugal e afirma a necessidade de se tornar independente diante de um marido que a isola dentro de casa:

\footnotetext{
Sou uma mulher dependente, as vezes acho que se tivesse um pouco de independência tudo seria melhor, e é por isso que estou te escrevendo pois sei que você é uma pessoa que se tiver ao seu alcance é incapaz de não ajudar alguém.

Eu vivo muito só, veja você que hoje, 09.03 é o dia de folga do meu marido, pois ele saiu de casa 9:00 hs da manhã e acabou de chegar agora 22:25 hs, se trancou na sala de televisão, e eu estou aqui agora, só angustiada te escrevendo, para te pedir que me ajude, eu preciso sair de casa para trabalhar, movimentar, viver.

Eu gosto de trabalhar, já trabalhei antes de me casar, só deixei porque a firma acabou, hoje não posso dizer que tudo está perdido pois existem pessoas que talvez possam me ajudar e é por isso que estou te escrevendo (APMQ. Carta de M. J., 9 de março de 1983).
}

A carta se inicia com a autora se definindo como uma mulher dependente e que se dirige a outra mulher, que seria um modelo destacado dentro da nova representação social do feminino que se consolidou nos anos de 1980: uma mulher forte, destacada socialmente e profissionalmente e que tem o comando da sua própria vida. Assim Marina Queiroz era vista por muitas telespectadoras. M. J. se vê representada por Marina, a ponto de ser encorajada a relatar suas experiências de sofrimento. E isso ocorre porque há uma identificação com a apresentadora. "É por meio dos significados produzidos pelas representações que damos sentido à nossa experiência e àquilo que somos. Podemos inclusive sugerir 
que esses sistemas simbólicos tornam possível aquilo que somos e aquilo no qual podemos nos tornar" (WOODWARD, 2014, p. 18).

M. J. revela na carta que já trabalhou e quer voltar a ser uma mulher que tem a própria renda, assim como Marina. É importante, ainda nesta análise, não deixar de considerar que a apresentadora está exposta num veículo de comunicação de massa, um dispositivo potente na disseminação de discursos. A figura da apresentadora não só é uma representação importante para M. J. como está em um lugar de fala que pertence às engrenagens de um mecanismo de fabricação desses discursos emancipatórios. Levando em conta que a televisão é uma mídia central no processo de construção da cultura, temos aí o cenário ideal para o estabelecimento da identificação. No que tange aos programas voltados para o público feminino, eles possuem este mecanismo de aproximação e confidência com a recepção ${ }^{6}$, seja ela de telespectadoras ou leitoras. Isso é um dos dispositivos mais fortes de convencimento e manutenção de audiência ou tiragens, no caso das revistas ou jornais, conforme Tânia de Luca (2012, p. 448):

\begin{abstract}
Atraentes e diversificadas, as revistas são procuradas e apreciadas por propiciarem momentos de entretenimento e prazer, bem conhecidos por quem folheia uma publicação colorida, com imagens bem cuidadas e que abordam questões do cotidiano, de maneira leve e interessante. Dentre as marcas distintivas desse gênero de impresso está a linguagem que se particulariza pelo tom coloquial, de alguém próximo e que aconselha, ampara, aplaca angústias, resolve dúvidas, sugere, fazendo as vezes de uma amiga e companheira à qual sempre se pode recorrer.
\end{abstract}

Marina era vista como uma amiga a quem se poderia recorrer e as cartas se tornavam o instrumento mais eficiente para isso. Em "A escrita de si”, Michel Foucault (2004) defende que a carta é um presente. O missivista dá para o destinatário um pouco de suas venturas e desventuras, sucessos ou fracassos, como se estivessem presentes fisicamente. Essa escrita atenua os perigos que a solidão pode trazer, apresentando a um outro olhar o que se pensou, o que se fez, o que se sente. É um ato de exercício do olhar e da subjetivação do discurso verdadeiro. É o traço no papel que torna o outro próximo:

Escrever é, portanto, "se mostrar", se expor, fazer aparecer seu próprio rosto perto do outro. E isso significa que a carta é ao mesmo tempo um olhar que se lança sobre o destinatário (pela missiva que ele recebe, se sente olhado) e uma maneira de se oferecer ao seu olhar através do que lhe é dito sobre si mesmo. A carta prepara de certa forma um face a face (FOUCAULT, 2004, p. 156).

Nessa perspectiva, a carta de M. J. foi a maneira que a autora encontrou para se aproximar da figura da apresentadora que, pela televisão, entrava em sua casa todos os dias. A carta serviu para encurtar as distâncias. M. J. se identificou com Marina, viu nela a possibilidade de conseguir um emprego e, por isso, precisava se fazer existente. Conforme observa Foucault (2004, p. 162), "no caso do relato epistolar de si mesmo, trata-se de fazer coincidir o olhar do outro e aquele que se lança sobre si mesmo ao comparar suas ações cotidianas com as regras de uma técnica de vida."

\footnotetext{
${ }^{6} \mathrm{O}$ termo recepção está sendo utilizado a partir de sua acepção nas ciências da comunicação, ou seja, para se referir ao público que consome o conteúdo midiático.
} 
A escrita desse tipo de carta é um momento, segundo Foucault, de introspecção, não apenas como um deciframento de si para si mas também como uma abertura de si para o outro. Ao contar de sua vida pessoal e da difícil relação com o marido, homem que a submete ao desprezo dentro da própria casa, M. J. decifra o próprio sofrimento para Marina na esperança de, assim, encontrar uma saída, uma solução.

Para ressaltar a influência que Marina exercia sobre uma parcela do público feminino que a assistia, selecionamos um cartão de Natal, cuja capa possui como ilustração a obra "Fachada" do artista plástico Alfredo Volpi. O texto é todo datilografado, enviado à apresentadora pela senhora R. A narrativa sintetiza a representação de Marina Queiroz como um estilo de mulher da década de 1980:

\begin{abstract}
Marina,
Quem a vê sabe que, como mulher e profissional, você cresceu incrivelmente nesses últimos anos, o que prova que é no exercício, na luta, na peleja do dia-a-dia que os talentos amadurecem, os trabalhos se aprimoram, a beleza se apresenta na sua forma mais perfeita, e a mulher encontra o sonhado nível de igualdade e respeito aos seus direitos e potencial que deseja!

Você, Marina, é mulher de especial importância nessa busca, porque é o exemplo vivo de resistência, da coragem, do começar de novo e de novo lançar-se de cabeça e coração na vida, rumo às melhores conquistas, maiores esperanças de viver o mundo íntegro na liberdade e no respeito às qualidades humanas.

Feliz Natal, em família e junto a toda a comunidade que vê o seu crescimento com alegria! Feliz ano de 88, e todas as vitórias que merece, todas as amizades que conquistou!

A amiga R. (APMQ. Mensagem de R.., dezembro de 1987).
\end{abstract}

Pelo cuidado da escrita, que atende à norma padrão, percebe-se que R. é uma mulher letrada, se comparada a M. J. e à autora da carta anônima Mas o mais importante no cartão de R. são os enunciados, que estão carregadas dos ideais defendidos pelos movimentos feministas da época, como a equidade de direitos, como vemos no trecho "a mulher encontra o sonhado nível de igualdade e respeito aos seus direitos e potencial que deseja!" Mais adiante, percebe-se novamente a influência de uma mentalidade progressista: "lançar-se de cabeça e coração na vida, rumo às melhores conquistas, maiores esperanças de viver o mundo íntegro na liberdade e no respeito às qualidades humanas". O uso da palavra liberdade é algo muito presente nos ideais dos movimentos feministas, uma vez que o desejo pela autonomia, pela liberdade de escolha, era muito evidente nos mais diferentes aspectos da existência da mulher. Algumas palavras mostram o posicionamento ideológico de quem escreveu, pelo uso de temos como luta, igualdade, respeito, resistência, conquistas.

As palavras são carregadas de historicidade, de um significado que as compõe ao longo do tempo e as relaciona a aspectos culturais; portanto, estes termos eram também frequentemente usados em artigos, discursos da imprensa feminista. ${ }^{7}$ Segundo M. Pêcheux (1975) não há discurso sem sujeito e não há sujeito sem ideologia. Para a Análise de Discurso, de acordo com Orlandi (1999), a linguagem se materializa na ideologia e a ideologia se manifesta na língua. É o que emerge nesse cartão, ao ressaltar a

\footnotetext{
${ }^{7}$ Constância Lima Duarte (2016) possui estudos sobre textos produzidos e divulgados na imprensa, diferenciando a imprensa feminina da imprensa feminista.
} 
independência e a força social e política de Marina, vista em outras mulheres da época. Vemos que Marina Queiroz influenciava e inspirava diferentes tipos de mulheres, com realidades sociais e culturais diferentes.

Embora fosse um programa destinado às mulheres, ele não era visto apenas por mulheres, conforme é possível constatar em muitas cartas assinadas por homens que integram o arquivo pessoal de Marina Queiroz. Os homens também eram uma parcela dos telespectadores e, nas correspondências escritas por eles, verificamos a hipervalorização da estética de Marina, que foi um ícone de beleza regional, vencendo vários concursos antes mesmo de se tornar uma apresentadora de TV.

Em setembro de 1985, Marina recebe uma correspondência na qual, em momento nenhum, fazse referência ao programa Revista Feminina, à sua competência profissional, a algum conteúdo apresentado ou sugestão de assunto a ser discutido. Trata-se de um pedido de casamento precedido por questionamentos que colocam em dúvida seu estado civil, conforme transcrevemos a seguir:

\footnotetext{
Querida Marina,

É com prazer que, escrevo essas linhas com alegria e respeito a você, morena bonita do Centro Cultural de Montes Claros.

Lembrando que a senhorita é uma gracinha de mulher, gostaria de saber quantos namorados já teve e, porque a fofura não casou até o momento, ou seja, porque a fofura não subiu ao "palanque sagrado", ao "pedestal do amor".

Se for por falta de pretendentes, então, aqui está um, se for por causa de falta de "momento oportuno", então, podemos dar um jeito, ou seja, poderemos construir um, juntos, obviamente. Falôu!

Pode me escrever; mas, vê se não me desiluda, coração (APMQ, Carta de I, 28 de setembro de 1985).
}

Ainda que exista uma intenção sincera de demonstrar um afeto especial a Marina, percebemos, nessa carta, vários pontos no discurso em que a condição de solteira aparece como um peso social para a mulher. O senhor I. evidencia ser apenas um telespectador, demonstrando desconhecimento da vida pessoal da apresentadora, pois, em 1985, ano em que a carta foi escrita, Marina já estava casada com o colega de trabalho, o radialista José Nardel. Além do tratamento excessivamente íntimo para quem não possui aproximação, com o uso de termos como "fofura", "gracinha de mulher", a primeira pergunta que ele se sente no direito de fazer está relacionada à quantidade de relacionamentos que Marina já teve, ou seja, se era uma mulher com comportamento reprovável: "gostaria de saber quantos namorados já teve." Não satisfeito, ele interroga o porquê de uma mulher que possui uma beleza que o agrada não ter se casado. Ou seja, na sua compreensão era incompatível uma mulher ser bonita e solteira. E continua a questionar "porque a fofura não casou até o momento, ou seja, porque a fofura não subiu ao "palanque sagrado", ao "pedestal do amor". É relevante destacar, nesse trecho, a importância que o senhor I. dá ao casamento. Para ele, o altar seria um "palanque sagrado", ou seja, um lugar onde é proclamado para toda uma comunidade que aquela mulher, a partir daquele momento, pertence a um homem, ou seja, tem um dono, não está disponível. A expressão "pedestal do amor" também imprime um tom santificado e de valor à mulher que casa, uma vez que pedestal é onde se firmam as imagens dos santos na igreja Católica; é algo que serve para elevar, para colocar em evidência. 
Após os questionamentos, o senhor I. passa a fazer julgamentos e dar soluções, como no enunciado “se for por falta de pretendentes, aqui está um”. Nessa passagem é possível perceber que a mulher tida como bonita mas que não se casa tem algo de errado. Está deixada de lado, não tem quem a queira ou não teve competência para conquistar um homem. Aí ele se apresenta para resolver o “problema”. E. caso não seja isso, e sim a falta de "momento oportuno", ele estaria disposto a-solucionar essa questão para ter Marina como mulher. O mais interessante desse trecho da carta é que, pela primeira vez, ele propõe que homem e mulher precisam pensar juntos essas questões e dá a Marina uma chance de opinar: "podemos dar um jeito, ou seja, poderemos construir um, juntos, obviamente. Falôu!" Os verbos vieram para a primeira pessoa do plural, "nós"; "podemos", "poderemos". A ideia de agir em conjunto é enfatizada com a palavra “juntos” e o sentido de consentimento por parte de Marina para tal situação é demonstrado na palavra "obviamente".

De onde vêm sentidos como esse da carta? Maia (2011) explica como o casamento civil, instituído no Brasil república, estruturou a dependência e subordinação da mulher, ainda que tentasse passar a ideia de equidade contratual. Além disso, o texto mostra como a representação social da "solteirona" tornou-se um instrumento de exclusão e terror moral. Destaca que o estado instituiu a desigualdade entre mulheres solteiras e casadas por meio de acesso a bens, ao trabalho e a outros direitos. Sem contar com a questão ideológica inserida nesse discurso, legitimada pelo código civil, de que o casamento era uma vocação inata da mulher. Apesar de que a obra faz menção às primeiras décadas do século XX, nenhuma mudança profunda nas representações sociais vigentes e cristalizadas se dá em um curto espaço de tempo histórico. Ainda nos anos de 1980, conforme vimos nas cartas analisadas até o momento, a preocupação por parte da população feminina com o casamento, decorrente do valor social negativo, construído culturalmente, em torno do da mulher divorciada ou "solteirona", estava presente.

Moscovici (2003) argumenta que qualquer representação social nova precisa da ancoragem para se estabelecer como um discurso de verdade aceitável, contido numa cultura. No caso da carta em análise, o que se percebe é que, apesar do ano ser 1985 e de que, em décadas anteriores, tenham aparecido discursos contundentes de desconstrução dessa visão de casamento e da relação homem e mulher, a ideia, no início do século XX, ainda estava muito enraizada, inclusive, de certa forma, em Marina, que guardou a correspondência por tantos anos.

Como Orlandi (1999) defende, discursos, como o próprio termo demonstra, "a palavra em curso", ainda que sejam divergentes, circulam pela mesma sociedade. E esses discursos têm a capacidade de promover manutenções e mudanças; movimentos ou permanências. Isso ocorre por causa da tensão entre a paráfrase e a polissemia. A paráfrase é o retorno aos mesmos espaços do dizer. E a polissemia joga com o equívoco e promove rupturas dos processos de significação, uma vez que isso é a condição do discurso. Sujeitos e sentidos são múltiplos e, se assim não fossem, não haveria necessidade de dizer mais nada. E é nesse movimento que há a transformação e a constituição de novos sujeitos. A falha da língua, a ruptura na realidade histórica e a influência da ideologia proporcionam um ritual com falhas e isso leva o sujeito a significar-se e significar. Nada é completo ou definitivo: A falha da língua, a ruptura 
na realidade histórica e a influência da ideologia proporcionam um ritual com falhas e isso leva o sujeito a significar-se e significar.

A incompletude é a condição da linguagem: nem os sujeitos nem os sentidos, logo, nem o discurso, já estão prontos e acabados. Eles estão sempre se fazendo, havendo um trabalho contínuo, um movimento constante do simbólico e da história. É a condição de existência dos sujeitos e dos sentidos: constituírem-se na relação da paráfrase e da polissemia (ORLANDI, 1999, p. 35).

\section{CONSIDERAÇÕES FINAIS}

Diante dos documentos selecionados do arquivo pessoal de Marina Queiroz, é possível concluir que o Programa Revista Feminina, cumpriu o seu objetivo, não só reforçando lugares tradicionais de ocupação da mulher, quanto promovendo a visibilidade de temas que interessavam à sociedade, na década de 1980, e que garantiam mais espaço e autonomia à mulher na sociedade. Marina, ao ocupar o cargo de apresentadora, estava em um lugar de fala privilegiado e, portanto, isso possibilitou que a sociedade que assistia ao programa identificasse, no Norte de Minas, mais um exemplo da nova representação social feminina existente em outros lugares do Brasil, consolidada na época e muito exposta por meio da mídia. Por isso, o conceito de representação social, sob a influência da psicologia social de Serge Moscovici, foi importantíssimo para compreender as relações estabelecidas pelas cartas e a forma como o(a)s telespectadore(a)s percebiam a apresentadora Marina Queiroz e as consequências de um veículo de comunicação ter como apresentadora uma mulher, ainda que em um programa que não fosse um telejornal. Marina, como uma mulher pública, de visibilidade social, ao mesmo tempo que reforçava estereótipos de gênero, propôs rupturas, não apenas pelos assuntos tratados em seu programa, mas também pelo sucesso como comunicadora e o envolvimento com a vida política. Uma trajetória de vida que não atingia um número ainda significativo de mulheres no Norte de Minas, mas que, no entanto, como pudemos ver nas cartas, influenciou e inspirou outras mulheres. Ter Marina Queiroz nesses espaços alimentava, no imaginário de muitas meninas e mulheres, o sonho de que elas também poderiam ocupar espaços semelhantes.

As cartas trouxeram ao presente as percepções mais sutis de algumas mulheres e homens nortemineiros dos anos oitenta. Nelas, encontramos variadas representações de gênero: a bela mulher, linda esteticamente e ideal para se casar e a mulher forte e poderosa, que apresentava um programa de TV, conhecia muitas autoridades na cidade e envolvia-se na política, um gueto muito masculino. Nenhum espaço social ocupado por mulheres sem grandes questionamentos, fora do ambiente privado, é algo que "sempre foi assim". Ao serem problematizadas na historiografia, vem à tona os muitos jogos de poder, disputas e desigualdades de gênero, ou seja, os muitos aspectos de um contexto histórico que foram as tramas alinhavadas pelo historiador ou pela historiadora. Fazer história das mulheres, reconstruir passados como esse de Marina Queiroz, promove a quebra de silêncio, a valorização do feminino, a inclusão da mulher em um contexto desenvolvimentista e abre espaço para que novas 
pesquisas nessa temática sejam empreendidas, visto que revelam a possibilidade de uma sociedade mais igualitária para o sexo feminino ao lado do masculino. Não somos o "outro"», não somos um ser pensado a partir de outro, temos e fazemos a nossa própria história. E Marina Queiroz lutou pela sua vaga nesse “jogo" tão disputado.

\section{REFERÊNCIAS}

ALMEIDA. H. B. de. Telenovela, consumo e gênero: "muito mais coisas". Bauru: Edusc, 2003.

BARSTED, L. de A. L. Legalização e descriminalização: 10 anos de luta feminista. Estudos Feministas, Florianópolis, Ano 0, n. 0, p. 104-130, 1992. Disponível em: https://periodicos.ufsc.br/index.php/ref/article/view/15804. Acessado em: 25 mai. 2020.

BEAUVOIR, S. O segundo sexo. Rio de Janeiro: Nova Fronteira, 2016.

BLOCH, Marc. Apologia da História on o ficicio do historiador. Rio de Janeiro: Zahar, 2002.

DINIZ, D. Aborto e contracepção: três gerações de mulheres. In: PEDRO, J. M.; PINSK, C. B. (org.). Nova História das Mulheres no Brasil. São Paulo: Contexto, 2012. p. 313-332.

DUARTE, C. Lima. Imprensa feminina e feminista no Brasil: século XIX. Belo Horizonte: Autêntica, 2016.

DUVEEN, G. Introdução: o poder das ideias. In: MOSCOVICI, S. Representaçoes Sociais: investigações em psicologia social. Petrópolis: Vozes, 2013. p. 7-28

FARR, R M. Representações sociais: a teoria e sua história. In: GUARESCHI, P. A.; JOVCHLOVITCH, S. (org.). Textos em Representaģões Sociais. Petrópolis: Vozes, 2012. p. 31-59;

FOUCAULT, M. A escrita de si. In: MOTA, M. B. de (org.) Foucault: ética, sexualidade, política. Rio de Janeiro: Forense universitária, 2004. p. 145-162. (Ditos e Escritos, V).

GOMES, A. M. T. Análise de discurso francesa e teoria das representações sociais: algumas interfaces teórico-metodológicas. Psicologia e Saber Social, v. 4, n. 1, p. 3-18, jul. 2015. Disponível em: https:/ /www.epublicacoes.uerj.br/index.php/psi-sabersocial/article/view/17558. Acessado em: 08 out. 2020.

JOVCHLOVITCH, S. Vivendo a vida com os outros: Intersubjetividade, espaço público e representações sociais. In: GUARESCHI, P. A.; JOVCHLOVITCH, S. (org.). Textos em Representações Sociais. Petrópolis: Vozes, 2012. p. 63-85.

LUCA, T. R. de. Imprensa feminina: mulher em revista. In: PEDRO, J. M.; PINSK, C. B. (org.). Nova História das Mulheres no Brasil. São Paulo: Contexto, 2012. p. 447-468.

MAIA, C. de J. A invenção da Solteirona: conjugalidade moderna e terror moral: Minas Gerais 1890-1948. Florianópolis: Ed. Mulheres, 2011.

MIELKE, A. C.; MOREIRA, D.; PITA, M. Oficinas formativas: liberdade de expressão e direito à comunicação. São Paulo: Intervozes, 2014. Disponível em: https://intervozes.org.br/projetos/ciclo-deformacao-liberdade-de-expressao-e-direito-a-comunicacao/.

\footnotetext{
${ }^{8}$ De acordo com Simone de Beauvoir (2016) o termo indica que a existência feminina foi historicamente definida apenas a partir do que foi negado na existência masculina, sem autonomia existencial.
} 
MOSCOVICI, S. Representações Sociais: investigações em psicologia social. Petrópolis: Vozes, 2013.

NICHOLSON, L. Interpretando o Gênero. Estudos Feminista, v. 8, n. 2, p. 9-42, 2000. Disponível em: https://periodicos.ufsc.br/index.php/ref/article/view/11917. Acessado em: 15 jun. 2020;

OLIVEIRA et al. O eu o corpo e a moda: reflexos dos anos 80. In: $11^{\circ}$ Colóquio de moda. $2^{\circ}$ Congresso Brasileiro de Iniciação científica em design e moda. Anais..., 2015. Disponível em: http://www.coloquiomoda.com.br/anais/Coloquio $\% 20 \mathrm{de} \% 20 \mathrm{Moda} \% 20$ -

\%202015/COMUNICACAO-ORAL/CO-EIXO4-COMUNICACAO/CO-4-O-EU-O-CORPO-E-

A-MODA.pdf. Acessado em: 15 ou. 2020

ORLANDI, E. Análise de discurso: princípios e procedimentos. Campinas: Pontes, 1999.

PERROT, M. As mulheres ou os silêncios da história. São Paulo: Edusc, 2005.

RAGO, M. Descobrindo historicamente o gênero. Cadernos de Pagu, Campinas, n. 11, p. 89-98, 1998.

Disponível em: https://periodicos.sbu.unicamp.br/ojs/index.php/cadpagu/article/view/8634465.

Acessado em: 10 mar. 2018.

SCOTT, J. Gênero: uma categoria útil para análise histórica. 1989. Disponível em: https://edisciplinas.usp.br/pluginfile.php/185058/mod_resource/content $/ 2 /$ G\%C3\%AAneroJoan\%20Scott.pdf. Acessado em: 13 maio 2020.

RICCO, F.; VANNUCCI, J. A.. Biografia da Televisão Brasileira. v. 1, São Paulo: Matrix, 2017.

WOODWARD, K. Identidade e diferença: uma introdução teórica e conceitual. In: SILVA, T. T, da (org.). Identidade e diferença: a perspectiva dos estudos culturais. Petrópolis: Vozes, 2014. p. 7-72. 
Data de submissão: 05/08/2020 Data de aprovação: $21 / 10 / 2020$ 